\title{
O retorno ao
}

\section{campo: uma}
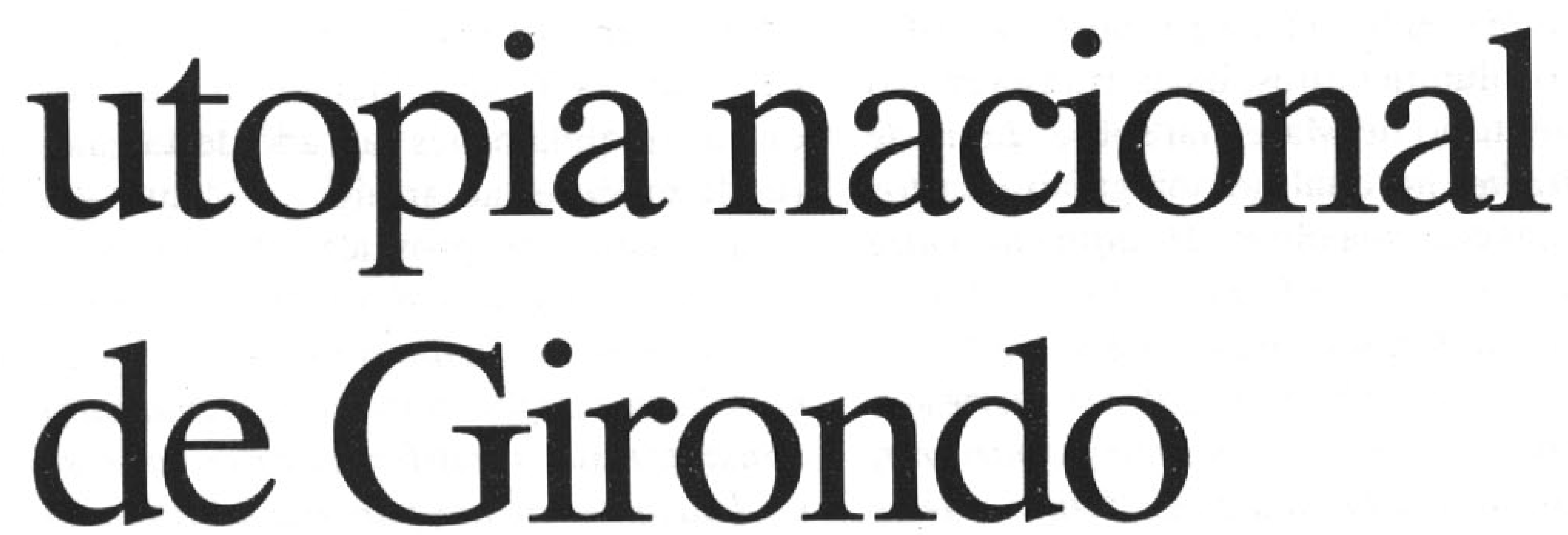

Nas últimas décadas doséculo XIX, afragmentação, a vertigem e a falta de certezas dominam o espírito da época. A arte compartilha este acúmulo de incertezas elaborando seus discursos segundoumalógicaestéticaquepassa pelasolidãoaristocráticadaboemia; ensaia na América Latina a formação de um sentimento continentalistae culmina nonossoséculocomosatos transgressores

ADRIANA RODRIGUEZ PERSICO é professora do Departamento de Letras Modernas da FFLCH-USP.

Tradução de Raquel La Corte das vanguardas.

Parece que em condições críticas a arte se preocupa com a questão da identidade. No caso da literatura argentina, essa questão tem a idade das lutas coloniais; os românticos discutiam a necessidade de se chegar à independência cultural e lingüística depois de conquistada a liberação política. Essa problemática recrudesce em duas conjunturas com características particulares: por volta de 1910 e em 1920. Nos anos 20 as vanguardas argentinas revelam, na construção de identidades, suas relações com a história político-social. A argentinidade que os pensadores do Centenário-Rojas, Lugones ou Gálvez-haviamimaginado como as fronteiras da nação fragmenta-se e limita-se a espaços 
menores como a cidade, o pampa, o bairro. A identidade inscreve-se em um território delimitado, numa geografia precisa onde circulam alguns personagens - o poeta, o imigrante, a prostituta, o trabalhador, a operária, o "malevo". Para delinear essa identidade que é ao mesmo tempo cultural e pessoal, os vanguardistas introduzem numa mesma constelação o novo, que equilibram com algumas tradições. A isso acrescentam a necessidade de aproximar a vida da arte, entendendo por tal uma prática antimercantilista, saudável e masculina (1). Para observar estes traços iluminadores, basta transcrever o comentário de Marechal sobre Luna de Enfrente no qual homologa ao escritor Borges com sua obra: "He aquí que, entre la actual garrulería musicante, sobre la oquedad de nuestros poetitas afeminados, late su pulso de hombres, alza su fuerte voz de hombreque sabe el pasado y el porvenir, y para quien la vida es un futuro que se desgaja, en la tristeza o en el júbilo pero siempre con manos de varón" (2).

No momento de citar um exemplo paradigmático de um texto no qual a aspiração pelo universal se junte à vontade nacionalista, impõe-se a produção de Oliverio Girondo, figura central da vanguarda argentina. Oliverio foi embaixador artístico, líder de seus contemporâneos e mestre de gerações posteriores. "En la poesía de Oliverio el bordado es europeo, es urbano, es cosmopolita. Pero la trama es gaucha" (3). O comentário de Mariátegui condensa uma definição - que se tornou lugar-comum - segundo a qual Oliverio Girondo encarna uma mistura muito argentina de localismo e cosmopolitismo; uma atualização, talvez, da dicotomia sarmientina de civilização e barbárie.

“ ¿Estupidez? ¿Ingenuidad? ¿Política?... 'Seamos argentinos', gritan algunos... sin advertir que la nacionalidad es algo tan fatal como la conformación de nuestro esqueleto." O lembrete de Oliverio não só coincide com Borges quanto ao caráter inevitável da nacionalidade (4), mas também acrescenta a posição da revista Martín Fierro (1924-27), baseada na célebre pesquisa sobre a provável existência de "una sensibilidad, una mentalidad argentina". As respostas insinuam as difíceis e contraditórias articulações que as vanguardas latino-americanas mantêm com as ideologias nacionalistas. A pesquisa completa a declaração de princípios consignados no manifesto que aparece no número 4 e que aposta encontrar uma nova voz amalgamada na conjugação de uma modulação própria dos sujeitos que, abrindo-se ao mundo, conseguem incorporá-lo no brutal ato de canibalismo cultural.

Nessa oportunidade Girondo cruza dois movimentos: por um lado, inventa uma genealogia prestigiosa que combina as letras com a política e as armas - assim, Sarmiento convive com Hernández, Cambaceres, Wilde, Guemes e Roca -, por outro, aniquila o viés sagrado desta galeria de próceres ao arraigar a identidade nacional em uma prosaica cotidianidade: "Yo creo en nuestra idiosincrasia, porque creo en eso que llamo mi existencia y no necesito de ningún esfuerzo intelectual para constatar sus manifestaciones, que se evidencian, al menos para mí, hasta el gesto con que me desabrocho los botines".

$\mathrm{Na}$ década de 30, Oliverio escolhe temas cosmopolitas, inclina-se por cortes abruptos e pelos ritmos cinematográficos enquanto Borges recita acentos crioulistas típicos da poesia do arrabalde. Em 1931, Girondo, regressando de uma longa peregrinação pela Europa e América, nos dá a conhecer Espantapájaros, um livro desaforado que, numa mistura entre poesia e prosa, dedica-se a destruir os bons costumes burgueses; a crítica dirige-se contra a rotina, as convenções, a fragmentação da vida e a normatização da arte. Os conceitos criticados pelo discurso aparecem em letra maiúscula: Família, Lei, Costumes, Arte. Contra eles o texto levanta as minúcias, o olhar focaliza o mínimo restituindo um estatuto perdido: "Preferí el sublimado a lo sublime" (5).

Espantapájaros questiona valores sociais e culturais quando opta pelo assassinato, o incesto, a impugnação das instituições e a ruptura da linguagem. É um livro crucial na produção de Oliverio na medida em que os textos posteriores se voltam, de alguma forma, para ele. A prosa constitui-se sobre a base de uma poetização do anquilosado cultural ou do "vulgar" coletivo. Nesse sentido mostraria como transformar em literatura o que não o é porque pertence a outros âmbitos ou porque dei- 
xou de o ser por desgaste. Ao mesmo tempo, o elevado é achatado por elementos baixos, insultos, alusões sexuais, mistura de registros e tons, sintagmas congelados.

Embora os martinfierristas aceitassem e proclamassem sérios compromissos estéticos, não mantiveram a mesma posição em relação à tomada de partido no plano da política geral. A dissolução da revista deveu-se em grande parte ao debate que dividiu as águas na campanha eleitoral de 1928. Entre os mais ferrenhos opositores ao embandeiramento político estava Oliverio Girondo. Borges colocou-se do outro lado.

Apesar disso, dúctil diante da conjuntura histórica, Oliverio abandona várias vezes seu tão conhecido apartidarismo. Em 1937 publica dois artigosem La Nación - "Nuestra Actitud ante Europa", no qual opõe a decadência européia à vitalidade da América, estabelecendo continuidades e quebras com o velho continente (6), e "ElMal del Siglo" em que desenvolve uma retórica nacionalista elaborando em chave jornalística os tópicos narrados em Interlunio. Trabalha neste último artigo o conceito de povo como sinônimo de terra e por isso o distingue de forma drástica de massa e de populacho, marcados por duas carências fundamentais: a irracionalidade e a atribuição sexual porque o vulgo para Oliverio é feminino. Em 1940, no folheto "Nuestra Actitud ante el Desastre", exorta a terminar a obra dos homens de maio, lutando contra a entrega do país e a selvageria do regime capitalista. Nacionalizar a economia, defender a cultura como indivíduos e como nação, reintegrar-se ao continente americano, tais são os pilares de seu programa de conscientização.

Em 1946 é publicado Campo Nuestro, um texto estranho na medida em que seus versos cultos, os entrelaçamentos de hendecassílabos, heptassílabos e pentassílabos, a atmosfera eglógica, o apaziguamento da linguagem, o tom religioso e a transcendência como pano de fundo configuram uma espécie de excrescência no corpus do escritor. O poema é um tipo de prece, uma confissão de ardente amor que o poeta dirige à campina argentina depois de transitar com distância irônica inumeráveis geografias urbanas.

Sabemos que as vanguardas outorgam um valor quase excludente ao olhar do artista que consagra ou rechaça enquanto propõe seus objetos de culto. De acordo com esses postulados, as produções de Oliverio, com exceção de Campo Nuestro, vão contra a lei, dissipam divisões conceituadas entre o certo e o errado, aniquilam pretensões de universalidade e deslocam a razão do lugar central. Nessa literatura que aprofunda uma estética da metamorfose como política lingüística da transgressão e encontra nessa mistura o valor poético supremo, coexiste com idêntico estatuto a maior parte dos elementos que povoam tanto a superfície como o interior da terra. $\mathrm{O}$ achatamento das hierarquias alcança os domínios humano, animal, vegetal e mineral. No lugar dos ídolos sociais são colocados subelementos pouco visíveis, habitantes minúsculos que evidenciam uma concepção estética e vital que descarta o binarismo como princípio doador de sentido. Dito de outro modo, o sistema que organiza o universo literário remete à imagem do caos, um estágio marcado pelo confuso e pelo impreciso. A literatura de Oliverio detém-se no momento anterior à ordem. As misturas de todo tipo fomentam a colocação em jogo de infinidades de alianças e, no entanto, descobrem a possibilidade de que convivam elementos díspares, estabeleçam uma relação horizontal entre os mesmos. A simbiose de materiais heterogêneos invalida toda centralização. Assim a literatura, no esforço por eliminar a oposição entre homem e natureza, torna-se ela mesma múltipla.

\section{"la total mezcla plena}

la pura impura mezcla que me merma los machimbres el

almamasa tensa las tercas hembras tuercas

\section{la mezcla}

sí

la mezcla con que adherí mis puentes." "La Mezcla"

Este poema que inicia En la Masmédula (1956) faz o balanço de sua obra anterior e prenuncia as reelaborações do último livro. Como encaixar essa escrita que assombra com fulgurantes heterogeneidades nessa outra textua- 
lidade que a fratura ao instalar-se na placidez do homogêneo? Campo Nuestro pertence a um Oliverio fugaz. A guerra estremece o poeta; que questiona a paisagem para desenterrar uma utopia perdida, voltando espantados seus olhos para o plano da ética. Em 1946, o gesto poético é de separação absoluta de tons e ritmos, porque se até esse momento a escritura transitava prazerosamente pelos tons do desafio e da ironia, aqui ela se veste de acentos nostálgicos que, apelando à tradição, adotam o recolhimento silencioso da prece. Quem reza sempre está de joelhos diante do objeto adorado, respeitoso e pronto para a próxima cerimônia religiosa. O rito que festeja Campo Nuestro modela-se sobre um nacionalismo rural que idealiza a paisagem até convertê-la em deusa.

$\mathrm{Na}$ década de 20 Borges descobriu as significações que podia abrigar a geografia e inventou dois novos ídolos topográficos: o pampa e o subúrbio. Mas, e aqui divergem os imaginários, os deuses para um agnóstico são criações, coisas arquetípicas. Quando a paisagem denuncia suas raízes culturais se torna artifício. Borges percorre a história da literatura argentina à procura de germes de lendas, descreve a consolidação dos mitos citando Ascasubi, Darwin, Hudson. Num movimento deambulatório que vai do meio rural ao urbano, e da cidade ao arrabalde, recolhe outros nomes - Fray Mocho, Evaristo Carriego, Gálvez, Arlt e se autoincluinessa história: "Cadauno denosotros ha dicho su retacito del suburbio: nadie lo ha dicho enteramente" (7).

O imaginário topográfico de Oliverio é radicalmente diferente; na sua matriz opera um encontro feliz - que chega, às vezes, à identificação entre natureza e cultura. Nas décadas de 1920 e 1930, sua poesia, que trança cosmopolitismo e nacionalismo, arraiga o local no concreto cotidiano e se compraz na dessacralização. A partir de Persuasión de los Días, o processo de abstração e interiorização que impregna a escrita se agudiza até desembocar num tipo de essencialização da matéria. Se o sujeito lírico de Veinte Poemas para Ser Leídos en el Tranvía (1922) ou de Calcomanías (1925) recortava pe- daços de paisagem percebidos com o olhar deslumbrado do homem do mundo, já nos anos 40 a viagem adquire outros sentidos. $\mathrm{O}$ que foi recolhido de cidades, praias e países que vertebram os primeiros textos se transforma em viagens internas, muitas vezes por mundos microscópicos e mostra a paixão por um nomadismo espiritual e íntimo. A viagem realiza-se pelo corpo e com o corpo, originando um intercâmbio permanente entre ambos porque, se o mundo çabe nas dimensões do corpo, este freqüentemente se torna cosmos. O plural circula pelo corpo, transita seus volumes, ocupa cavidades e escorre até o exterior:

\section{"No soy yo quien éscucha ese trotellovido que atraviesa mis venas. La lluvia con frecuencia, penetra por mis poros,}

\section{el ritmo de las gotas \\ que manan de mi carne".}

"Nocturnos"

Não só mudam os espaços interiores como também os externos: a natureza substitui as antigas cidades reconhecidamente culturais. A cenografia preferida da modernidade - a cidade -, esse lugar de experiências inusitadas e centro de aventuras vertiginosas, desaparece e com ela se desvanece também o flâneur. O olhar fotográfico e acumulativo cede diante do olhar contemplativo próprio do espírito religioso. Nessa troca de posição do ponto de vista, começa a construção de um imaginário nacionalista que defenestra qualquer tentativa de cosmopolitismo. Enquanto na década de $20 \mathrm{a}$ argentinidade se arraigava na vida cotidiana e urbana e numa cultura que somava nomes e armava famílias de antecessores e herdeiros; enquanto nesse momento a nacionalidade tinha que ver com uma fonética - com a voz - e com certos gestos; em 1946 ela é um tema a ser declamado em ritmos clássicos. As diferenças são notáveis: vão do concreto à idéia, da irreverência ao respeito e do construído ao não-criado.

Em 1937 aparece Interlunio, o único relato de Oliverio. Com seu conhecido humor corrosivo, Girondo se diverte parodi- 
ando o modelo realista em cujo esquema o escritor pobre e fracassado, depois de sofrer o vazio existencial, encontra consolo no retorno à plenitude da natureza. As breves anedotas que contam a vida do poeta repetem tópicos folhetinescos - entre outros, a tragédia do estrangeiro rodeado por uma aura de mistério - e narram o destino adverso do artista numa seqüência que parte da morte do pai, passa pela falência econômica e culmina com a fome e o exílio. O final abre a duas possibilidades igualmente absurdas e hilariantes: o êxito editorial ou a morte heróica. Se Espantapajaros pode ser lido numa superposição de palavras, numa coincidência entre a enunciação individual e a coletiva, também Interlunio pode ser interpretado a partir da reconstrução de certos ditos e imagens socializadas para se chegar à geração de estereótipos, como o da pureza americana que se destaca como território paradisíaco contra uma Europa corrupta ou o que representa o país sob a figura pedestre de uma vaca (8). Com este uso particular, com o emprego da linguagem socializada e da imagem, a escrita de Oliverio destrói qualquer concepção oficiosa: nem mimese nem linguagem elevada, nem criação ex-nihilo.

Entre as vertiginosas geografias urbanas européias e americanas das primeiras produções e a austeridade imutável da campina de Campo Nuestro, Interlunio acompanha o deslocamento do protagonista da cidade para o arrabalde:

\section{"Las capitales europeas carecen de límites} precisos, se amalgaman y se confunden conlospueblosquelascircundan. Buenos Aires, en cambio, en ciertos parajes porlo menos, termina bruscamente, sin preámbulos. Algunas casas diseminadas, como dados sobre un tapete verde, y de pronto: el campo, un campo tan auténtico comocualquiera. Pareceríaque el arrabal no se animara a distanciarse del adoquinado" (I., pp. 257-8).

Nessa espécie de peregrinação até as origens, o poeta encontra respostas a seus questionamentos numa vaca que fala com a voz de sua mãe (9).

Mas o que Interlunio parodia - esses constituintes da nacionalidade que entram na literatura num gesto abrangente e ousado, já que conjugam o cristalizado da cultura com um afã de achatamento poético - em Campo Nuestro muda de signo. Os enunciados viajantes, típicos de Oliverio, fazem retroceder a zombaria e propõem a ressacralização:

“'No eres más que una vaca - dije un día con un millón de ubres maternales'... sin recordar-!perdona! - que enarbolas entre el lírico arranque de tus cuernos un gran nido de hornero".

Oliverio retifica a versão de Interlunio pelo menos em três momentos: no primeiro escuta o chamado, desta vez feminino, do campo que o exorta com voz de mãe a deixar o mar, lugar equivocado, que desvia o sujeito e o leva em direção a outras paisagens. No segundo momento pede perdão pela zombaria que contém a definição "un millón de ubres maternales". Por último, há a referência à paisagem onde o poeta fracassado elogia a ausência de mortes do pampa em comparação com a multidão de cadáveres em terras européias.

A imagem da vaca já está presente no texto 16 de Espantapájaros onde a metamorfose é uma estratégia para retorcer as convenções literárias e sociais e limitar um espaço textual que é concebido como puro vir a ser. Ao mesmo tempo a língua escolhida surge da convergência entre o coletivo e o individual. De fato, todo caráter pessoal se neutraliza quando estes dois tipos de palavras se tocam. A confluência de vozes faz retroceder a concepção de uma voz original. Creio que nesse ponto aparece a marca da nacionalidade: no reconhecimento das dívidas que a própria palavra tem com a anonímia comunitária Oliverio oferece, nesse momento de sua produção, uma definição do conceito.

Em Campo Nuestro, a idéia de argentinidade é diferente. $\mathrm{O}$ título de óbvias ressonâncias católicas aparece nos primeiros e nos últimos versos; e no meio uma descrição do campo, saturada de epítetos devotos, obriga a uma leitura transcendentalista. A paisagem concentra a totalidade do espaço - mar, terra e céu - assim
8 A narração pōe em evidência alguns lugares-comuns tais como: "el poeta es una sombra", "los ruidos matar", "todo poeta habla un lenguaje para iniciados", "la naturaleza es la madre a la que hay que retornar".

9 Antes, o narrador comenta: "Es así como, antes de embarcarse para la Argentina, ya se la representaba como un enorme vaca con un millón de ubres rebosantes de leche[...]" (p. 250). 
como a totalidade do tempo e marca o início não só de uma história fechada no descobrimento, mas também destaca o começo de alguns vestígios primitivos de vida; ou, o que dá no mesmo, investiga os rastros que a história funde na natureza: las

"No olvides que el azar hinchó sus ve-

y a través de otra mar dio en tus riberas.

Ante el sobrio semblante de tus llanos se arrancó la golilla el castellano.

Tienes, campo, los huesos que mereces: grandes vértebras simples e inocentes, tibias rudimentarias,

informes maxilares que atestiguan tu vida milenaria".

A harmonia entre as duas esferas muda de dimensão passando do âmbito macroscópico para o âmbito pessoal. Assim o campo se transforma em memória individual e oferece um ensinamento particular ao sujeito lírico. História particular e íntima, vida coletiva e experiências infantis, o campo é um espaço dilatado, protetor e fraternal.

Se em Interlunio Oliverio injeta energia no estereótipo quando recontextualiza a imagem do país pecuarista, em Campo Nuestro, a ironia, revisitada, deixa de o ser, absorvida por uma trama de valores que destacam em primeiro plano a essência da nacionalidade. E mesmo sendo hegemônico o paradigma religioso, há outro, que introduz sub-repticiamente a tradição literária. No poema, o culto à masculinidade entra pela mão da literatura gauchesca; desse modo o campo benigno e eucarístico é também macho e bravo. A nacionalidade demarca um território que se interioriza no dizer e no fazer gauchos:

\footnotetext{
"Cuando me acerco, pampa, a tu recuerdo,

te me vas, despacito, para adentro

al trote corto, campo, al trotecito".
}

Em dezembro de 1950, Oliverio publica em La Nación um poema retirado de suas obras completas, Versos al Campo, que se trata de uma queixa desiludida à falta de resposta à prece de Campo Nuestro. Versos al Campo faz um contraponto com o texto anterior a partir da antidefinição que abre: se o tempo era tudo agora não é nada. Instalado nesse lugar evanescente, o olhar lírico atualiza a distância irônica juntando à série anterior o epíteto "surdo". Se o campo constituía um espaço pleno, uma presença constante, se havia uma identificação entre o sujeito e a paisagem a ponto dela ser considerada um princípio muito anterior à cultura, agora ela se transforma num lugar efêmero que anseia desertar de sua condição; o campo não escuta a voz de seus habitantes assim como o poeta não entende a linguagem da paisagem. Os diálogos, a comunhão entre o homem e a natureza são abolidos. Sendo que não há reconciliação, os chamados, venham estes da natureza ou do ser humano, são vãos.

Os ritmos e tons prenunciam En la Masmédula. O desaparecimento de todos os elementos naturais culmina com a pergunta metafísica que encerra a composição juntando os opostos:

"Seva.

No quiere ser campo.

¿Hambre de cielo o de nada?”.

Distante dos acentos nostálgicos de 1946, Oliverio sustenta, contudo, idêntica sede de absoluto. Poeta dos limites, amante das tensões e incitador das opções mais vitais sob os modos mais extremos, em Versos al Campo, Girondo faz uma autocrítica de sua composição clássica, reescrevendo-a. Há que se esperar ainda dez anos até a aparição de En la Masmédula, para que a literatura de Oliverio reassuma sua capacidade provocadora com a invenção de uma língua cortante e excessiva feita de pedaços e acúmulos. Quando chegar esse momento, as preocupações com a nacionalidade transformar-se-ão na obsessão apaixonada por uma linguagem eternamente mutante a ponto de excluir qualquer outra busca. Afastada das essências, a linguagem se rende diante da mais pura materialidade. 